PARTIOAS OF THIS REPORT ARE ILLEGIELE.

It has bec. reprotuced from the best cuailable copy to permit the broadest

- ssible avaitability.

UCRL- 91568

PREPRINT

OUNF - SU1 $218-\infty)$

\title{
NEUTRAL BEAM INJECTOR OXYGEN IMPURITY MEASUREMENTS AND CONCENTRATION REDUCTION VIA GETTERING PROCESSES
}

R. J. Kane, H. L. Hsu, R. G. Kerr,

B. E. Mills, P. Poulsen, S. Hibbs

This Paper Was Prepared For Submittal To

The American Vacuum Society

31 st National Symposium, Reno, Nevada

Dec. 3-7, 1984

October 1984

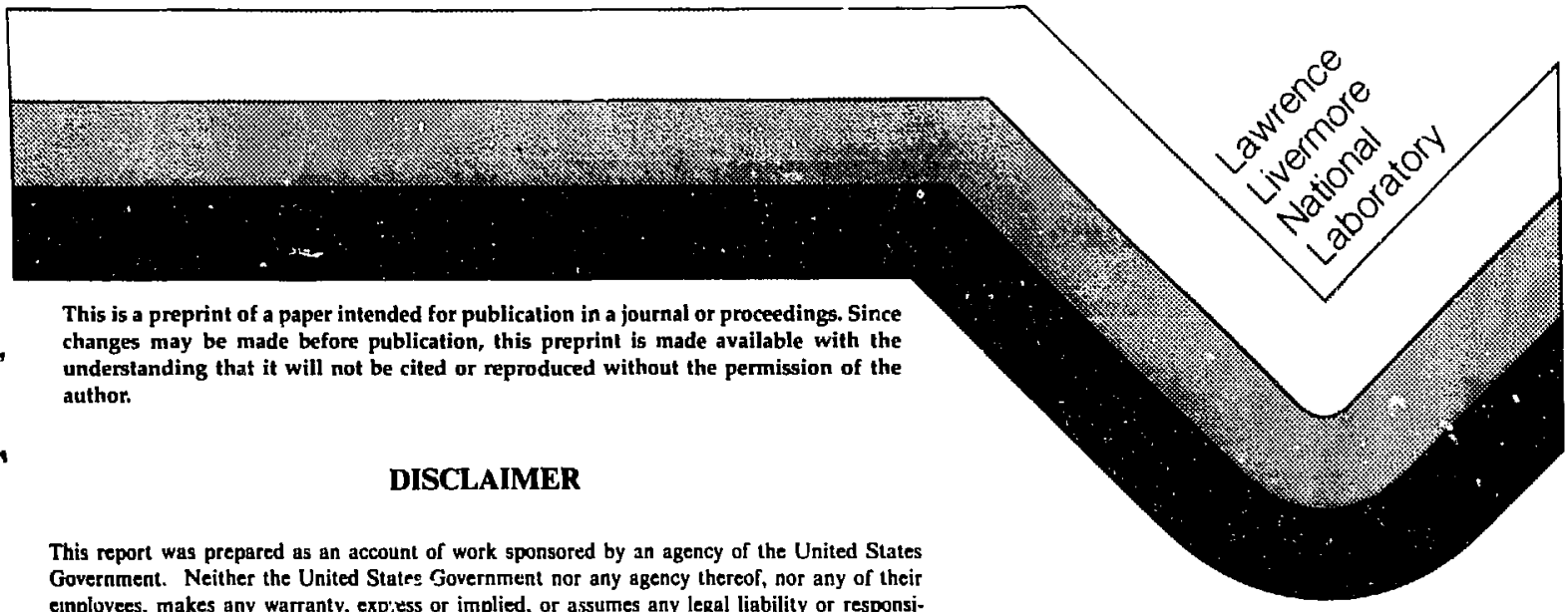
employees, makes any warranty, expiess or implied, or assumes any legal liability or responsjhility for the accuracy, completenes, or usefulness of any information, apparatus, product, or process disclosed, or represents that its use would not infringe privately owned rights. Reference herein to any specific comme:cial product, process, or service by trade name, trademark, manufacturer, or otherwise does aot necessarily constitute or imply its endorsement, recommendation, of favoring by the linited States Government of any agency thereof. The views and opinions of authors enpresed herein do not necessarily state or reflect those of the United States Government or any agency thereof.

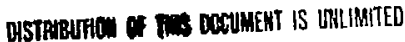


NEUTRAL BEAM INJECTOR OXYGEN IMPURITY MEASUREMENTS

AND CONCENTRATION REDUCTION VIA GETTERING PROCESSES

R. J. Kane, W. L. Hsut, R. G. Kerr, B. E. Millst, P. Poulsen, and S. Hibbs

Lawrence Livermore National Laboratory, University of California Livermore, CA 94550

\section{ABSTRACT}

The reduction of oxygen impurity levels by means of gettering within the arc chambers of the TMX-U neutral beam injectors has been measured. The TMX-U Neutral Beam Test Stand was used for this experiment. Analys is incorporated silicon surface probes and optical Doppler-shift measurements of the Lyman alpha spectra of deuterium atoms with energies appropriate for $\mathrm{D}_{2} 0$ parentage. Without gettering, the Auger electron spectroscopy analysis of an exposed silicon sample showed a large oxygen feak below the surface peak with a concentration equivalent of approximately $2 \%$ for an accelerated beam. After gettering, with either titanium or chromium getters, the oxygen concentration was reduced by at least a factor of 10 according to optical monochromator data, and at least a factor of 8 from Auger spectroscopy data. Simultaneously, other metallic impurities were not increased substantially as a result of gettering. Additional effects observed during this study include a change in the accelerated deuterium species concentrations, loss of gettering activity and arc operation, and a change in arc performance from arc chamber gas absorption during operation. 
PURPOSE

Neutral beam injector systems are used for heating the magnetically confined fusion plasmas in tokamaks and mirror machines. In these systems hydrogen (H) or deuterium (D) gas is the source of ions to be accelerated through a large negative potential. These ions pass through a region of cold gas and are neutralized by charge exchange before entering the experimental region as a neutral particle beam. One consequence of starting with an ionized gas arc chamber is the acceleration of oxygen (0) along with the desired beam particles. The 0 content in injectors of this type is generally around 2 to $3 \%$ and is the largest impurity component. Trapping of beam-injected impurities can cause undesirable enhanced scattering and trapping of ions in the thermal barrier region.

The use of titanium (Ti) meial film evaporated onto the inside of an arc chamber as a getter for 0 was reported previously. ${ }^{1}$ This idea formed the basis for investigating gettering as a means to reduce the 0 content in the injectors used on the Tandem Mirror Experiment-Upgrade (TMX-U) at Lawrence Livermore National Laboratory (LLNL). Specifically, the getter would serve as a covering material to prevent 0 from being liberated from the walls during operation. Our test method, results, and analysis are discussed in the later sections of this paper.

EXPER IMENTAL MODEL

Oxides on the arc chamber wall and 0 diffusing through the walls are sources of arc plasma contamination. Arc chamber vacuum seal leaks and 0 in the main vessel are sources as well. 
0xygen from the surfaces of the walls is removed fairly rapidly during neutral beam injector operation (tens of shots) and the 0 percentage drops to approximately $2 \%$. Very low concentrations are achievable after large numbers (thousands) of shots or long pulses have occurred. However, conditioning an injector assembly over this length of time on the main experimental apparatus is not appropriate. We operate 24 injector systems on TMX-U with about 10 spare injector assemblies. Assemblies are replaced as they fail so it is highly probable that at least one injector is accelerating large concentrations of 0 into the target plasma. Gettering buries any 0 on the walls and absorbs free 0 in the arc chamber. As the getter layer becomes saturated, it can be re-covered by evaporating a new layer of the metal film.

The TMX-U Neutral Beam Test Stand (Fig. 1) was used in our experimeric for the operation of the injectors and the acquisition of necessary data. The Test Stand is normally used for the characterization and the conditioning of injector assemblies. Silicon (Si) targets were provided by Sandia Laboratories (Livermore) to estimate the impurity levels through Auger spectroscopy analysis.

The gettering film is deposited hy heating a titanium-tantalum ( $\mathrm{Ti}-\mathrm{Ta}$ ) alloy wire (strung around the periphery of the arc chamber) to incandescence. The evaporated metal film covers all metal surfaces but not the insulating regions because of shadowing. The presence of $T i$ on these surfaces was not considered to be a problem because the filaments evaporate tungsten $(W$ ) as a result of their normal operation.

\section{OBSERVATIONS}

Optical spectroscopy showed that the 0 component related to $\mathrm{D}_{2} \mathrm{O}$ was riduced to approximately $0.2 \%$ or less after a getterilig film had been 
deposited. Analysis involves first removing a linear background and then fitting separate Gaussian curves to each peak. The curve its are generated by using the counts in 5 to 7 of the spectral channels that minimize the error due to the overlaps. The beam composition is determined by integrating the curve fits over a channel bandwidth of 40 channels and then correcting for the cross section and dissociation number of the species being analyzed. The q'antities of each species are then summed and their percentage determined. Figures $2(a)$ and $2(b)$ show the optical spectra for hydrogen Lyman alpha transitions before and after the gettering. The accelerated beam had a 16-kV peak voltage component and a power supply current of about $45 \mathrm{~A}$ for $75 \mathrm{~ms}$. On successive shots after gettering, the gettering became less effective. The trend toward the non-gettered state is shown in Fig. 3(a) and 3(b) for Ti and chromium (Cr) gettering, respectively.

The effect on the accelerated ion concentration is significant. When $\mathrm{Ti}$ film is used, the full- $\left(0^{+}\right)$and half-energy $\left(D_{2}^{+}\right)$components increase at the expense of the third-energy $\left(\mathrm{D}_{3}^{+}\right)$and impurity $\left(\mathrm{D}_{2} \mathrm{O}^{+}\right)$components, increasing the mean velocity of the ion beim. Chromium causes the third-energy component to be enhanced with respect to the full-energy component, reducing the percentage of the higher speed components. In addition, the arc density varies as a function of time during a shot and, presumably, as the D saturates the $T_{i} f_{i l m}$.

We found that for experimental operations, a getter-film deposition every fourth shot would be adequate for TMX-U. Increased deposition frequency could be implemented when studying the effects of impurities on the plasmas. A regular cycle of gettering stabilizes the operation of the injector during experimentation because the gettering film changes operation of the arc chamber during the shot. Thus, regular getter cycles would aid in minimizing 
the variation from one shot to the next. Figures $4(a)$ and $4(b)$ are photographs of the power supply waveforms before and after gettering with Ti. Note the rapid decline in the arc density, $n_{i}$, and subsequent recovery when the Ti film is used. This behavior may be caused by the ion pump action at the walls, which is enhanced when $T i$ is present. This effect is normally visible during non-gettered operation.

A cross-check of the concentration of 0 and a check for other impurities from the gettering were established through the use of Si surface samples and analysis via Auger electron depth profiling. This method was capable of analyzing the total 0 content whereas the optical technique was sensitive to only the $\mathrm{O}_{2} \mathrm{O}^{+}$component.

Silicon disc samples, $7.7 \mathrm{~mm}$ in diameter and $0.6-\mathrm{mm}$ thick, were exposed to the beam current upon insertion through a valve in the vacuum tank in front of the calorimeter. Each sample was inserted on a probe ar.w held in thermal contact to provide inertial cooling before being exposed to 20 beam shots. Each exposure lasted $30 \mathrm{~ms}$. The injector produced about 15 atomic $\mathrm{A}$, at $16 \mathrm{kV}$ with a cross-sectional area of approximately $200 \mathrm{~cm}^{2}$. A gettering film was deposited in the arc chamber after every fourth beam shot.

Following exposure, the samples were removed and transported to the surface analysis chamber. The carbon (C) and 0 depth profiles were determined, using Auger depth profiling on the Si discs. A 5-kV, approximately 10-uA electron beam and a 1-keV Ar ion beam were employed. The ion beam was rastered across the sample with an amplitude that produced a current density of $25 \mathrm{uA} / \mathrm{cm}^{2}$, resulting in a Si sputter rate of approximately $2.3 \mathrm{~nm} / \mathrm{min}$.

The near-surface 0 and $C$ concentration profiles in atomic percentages are shown in Fig. 5 as solid and dashed lines, respectively. Cases (a), (b), and 
(c) correspond to samples exposed when the arc chamber was gettered with $\mathrm{Ti}$, ungettered, and gettered with $\mathrm{Cr}$. At depths less than a few nm all the samples are very similar, showing contamination caused by atmospheric exposure when the samples were transported. Case (d) corresponds to the $D$ and $C$ profiles taken on an unexposed control sample.

The reduction of 0 by gettering is immediately evident. In the ungettered case (b), there is an 0 peak below the surface peak. The peak is centered near $17 \mathrm{~nm}$, which corresponds to the range of several keV energetic 0 . With either $\mathrm{Ti}$ or $\mathrm{Cr}$ getter films, shown in cases (a) and (c), the 0 peak disappears and the overall 0 concentration is reduced by at least a factor of 8. The results of the gettering process are consistant with a model where oxygen is trapped on the walls by the metal film. The optical analysis and the Auger spectroscopy analysis agree because the impurities are dominated by the $\mathrm{D}_{2} \mathrm{O}^{+}$and $\mathrm{DO}^{+}$components. 1,2 Note the increased background levels of $\mathrm{C}$ and $\mathrm{O}$ in the geitering cases ccmpared to the background level in unexposed $\mathrm{Si}$ [Fig. 5(d)], which may be due to the knock-on of surface contaminants by the high flux of deuterium.

Integrating the 0 profile in case (b) gives a total implanted 0 concentration of $3 \times 10^{15}$ atoms $/ \mathrm{cm}^{2}$. The total number of injected hydrogen beam atoms, over 20 exposures, was estimated to be $2.8 \times 10^{17}$ atoms $/ \mathrm{cm}^{2}$. Taking the ratio of these numbers gives an impurity concentration in the beam of $1.1 \%$, which agrees with earlier independent estimates. 1,3 The heating of the sample by the incident beam is not expected to cause diffusion of 0 into the sample. ${ }^{4}$ However, this effect would not reduce the total number of 0 atoms trapped in the sample.

The $C$ depth profiles are also shown in Fig. 5; there does $t$ appear to be a substantial change from one case to the next. Auger electron spectra 
were examined on the surface of each sample, and there were no detectable levels of either $\mathrm{Ti}$ or $\mathrm{Cr}$. The effect of gettering therefore reduced the level of 0 without increasing the impurity levels of other elements. Titanium and $\mathrm{Cr}$ performed equaliy.

\section{REALIABILITY}

The reliability for this process was of concern. Changing an injector assembly involves considerable time ( 4 hours) and must be performed when the machine is not operating. Our experimentation included a 500-shot life test for the getter wire under conditions similar to what we expected in use of the machine. No significant degradation was noted in the performance of the getter wire, and the buildup of Ti caused no noticeable effects in the arc performance. Flaking of the material from the walls was not observed either during operation or during a visual examination after the life test.

Chromium was also used for a short time and some tendency to flake was noticed after 30 to 50 getter shots. Because we had no significant experience with $\mathrm{Cr}$ in this application, we chose to abandon it in favor of $\mathrm{Ti}$.

The lifetime of a Ti getter wire used under the conditions of our life test (2000 beam shots) was the same as that of the entire getter system. Nevertheless, a staggered maintenance cycle was planned to prevent failures from occurring within a short time and to reduce the number of injectors in the shop for getter replacement. 
CONCLUSIONS

Gettering reduces $\mathrm{D}_{2} \mathrm{O}^{+}$impurities in ion beams by approximately a factor of 10, and the total 0 impurity concentration may be reduced by a factor of eight. Experimentation with plasma impurities appears possible with gettering as a means of controlling the impurity level. Surface analysis and optical spectra agreed in the level of improvement.

However, several problems were encountered during our testing. One problem was the change in operation of the injector output beam during the shot because of absorption of the $D$ in the arc chamber by the getter film. Another problem was the variation in arc density from one shot to the next. However, both problems can be controlled by regular getter operation. Reliability is a potential problem, but maintenance will minimize it. Finally, although getter materials other than $\mathrm{Ti}$ and $\mathrm{Cr}$ may improve performance, we prefer to use $T i$ because of our ongoing experience with it. 
ACKNOWLEDGMENTS

The authors wish to thank Ken Autio, Chuck Gilliam, and the rest of the Neutral Beam source group who fabricated and operated the units that were a part of this experiment.

This work was performed under the auspices of the U.S. Department of Energy by the Lawrence Livermore Nationa? Laboratory under contract number $W-7405-E N G-48$.

\section{REFERENCES}

1. W. Ott, K. Freudenberger, F. P. Penningsfeld, E. Probst, and R. Seuss, "Reduction of the Impurity Concentration of an Intense Hydrogen Ion Beam," Rev. Ści. Instrum., 53, 82 (1982).

2. S. Tanaka, M. Akiba, H. Horiike, M. Kuriyama, S. Matsuda, M. Matsuoka, Y. Ohara, T. Onga, Y. Okumura, K. Shibanuma, T. Shibata and H. Shirakata, "Prototype Ion Source for JT-60 NBI," Proc. Ninth Symp. Engineering Problems in Fusion Research (IEEE, New York, N.Y., 1981) pp. 1342-1346).

3. T. J. Orzechowski, M. R. Carter, and R. P. Munger, Characteristics of the Neutral Beam Injectors for the Tandem Mirror Experimert-Upgrade, Lawrence Livermore National Laboratory, Livermore, CA, UCR.L-88759 (1983).

4. R. C. Newman, J. H. Tucker, anci F. M. Livingston, J. Phys. C: 16, L151 (1983). 
Fig. 1. Neutral Beam Test Stand. The equipment shown here, with the exception of the Optica) Multichannel Analyzer (OMA), is used for conditioning and characterizing the injector assemblies for TMX-U. The secondary emission detector is designated by SED.

Fig. 2. Optical Doppler-shift spectrum before (a) and after (b) gettering. Increasing wavelength is to the right on the horizontal axis.

Fig. 3. Comparison of the effects of $T i(a)$ and $\hat{C r}(b)$ gettering on the ion beam for the designated species.

Fig. 4. Effect of gettering on are voltage $v_{a r c}$, current $I_{a r c}$ and chamber density $n_{i}$ before (a) and after (b) gettering with Ti.

Fig. 5. Auger spectroscopy depth profiles of a beam-illuminated silicon surface for a sample exposed to an arc chamber gettered with $\mathrm{Ti}(\mathrm{a})$, ungetiered (b), and gettered with $\mathrm{Cr}(c)$. The solid and dashed lines represent 0 and $c$ concentration in atomic $\%$, respectively. Case (d) corresponds to an unexposed sample. 
R. J. Kane - Figure 1

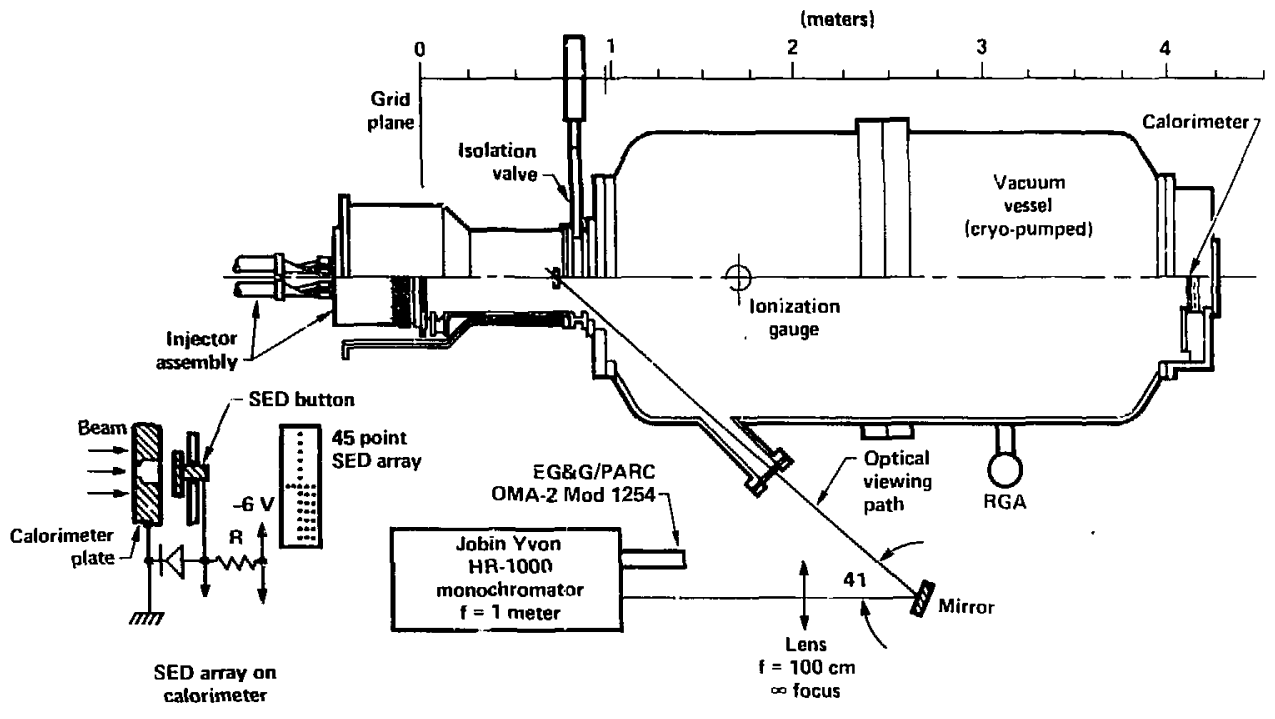


R. J. Kane - Figure 2

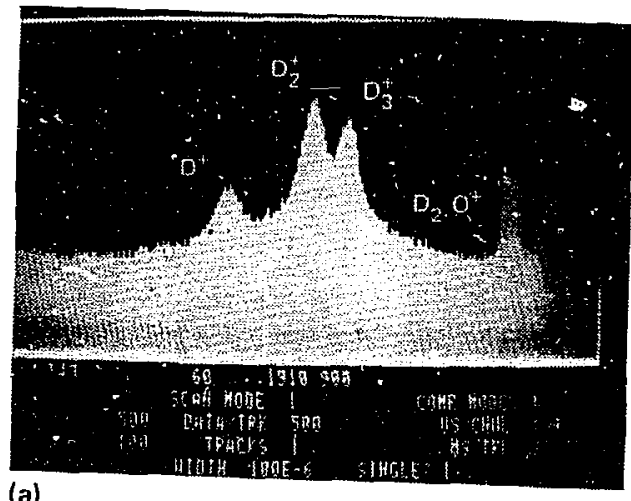

(a)

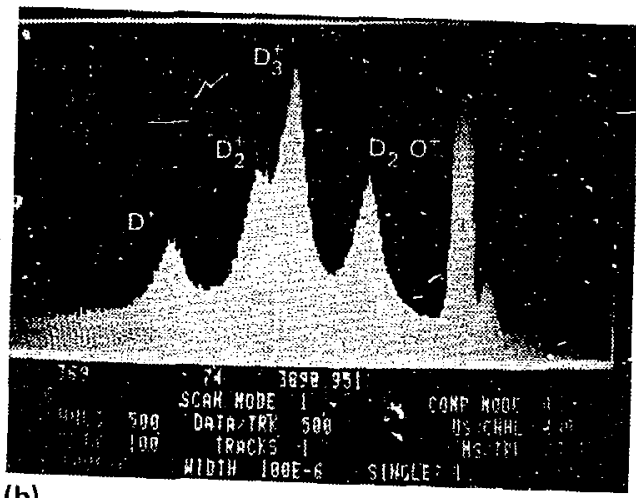

(b) 
R. J. Kane - Figure 3
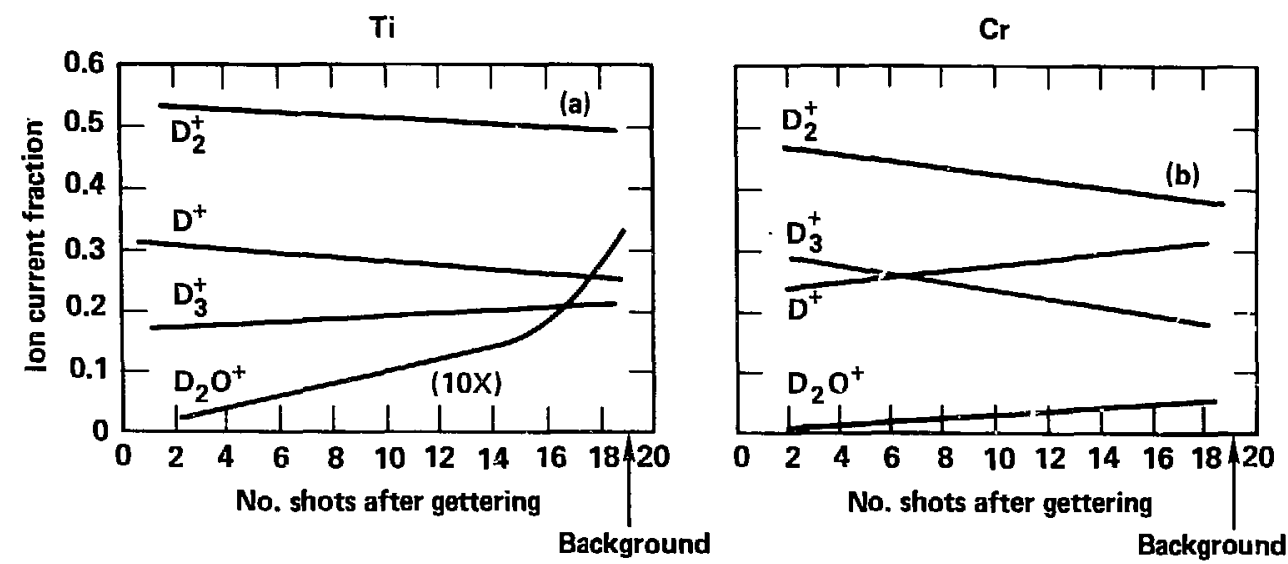
R. J. Kane - Figure 4

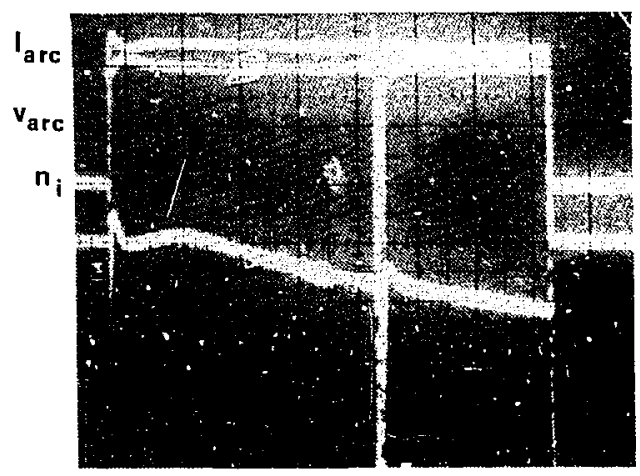

(a)

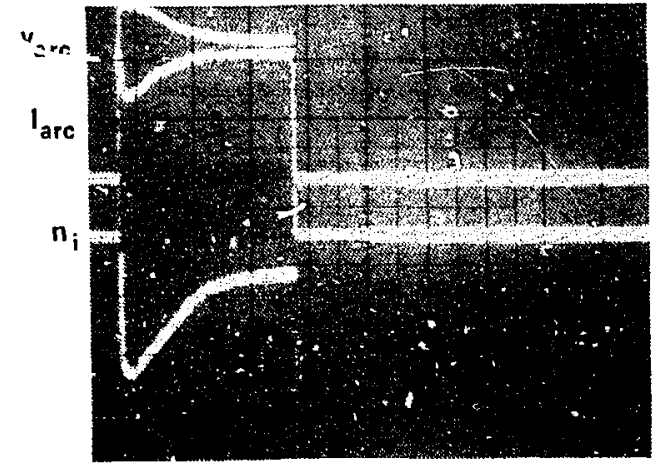

(b)

Time $\longrightarrow$ 


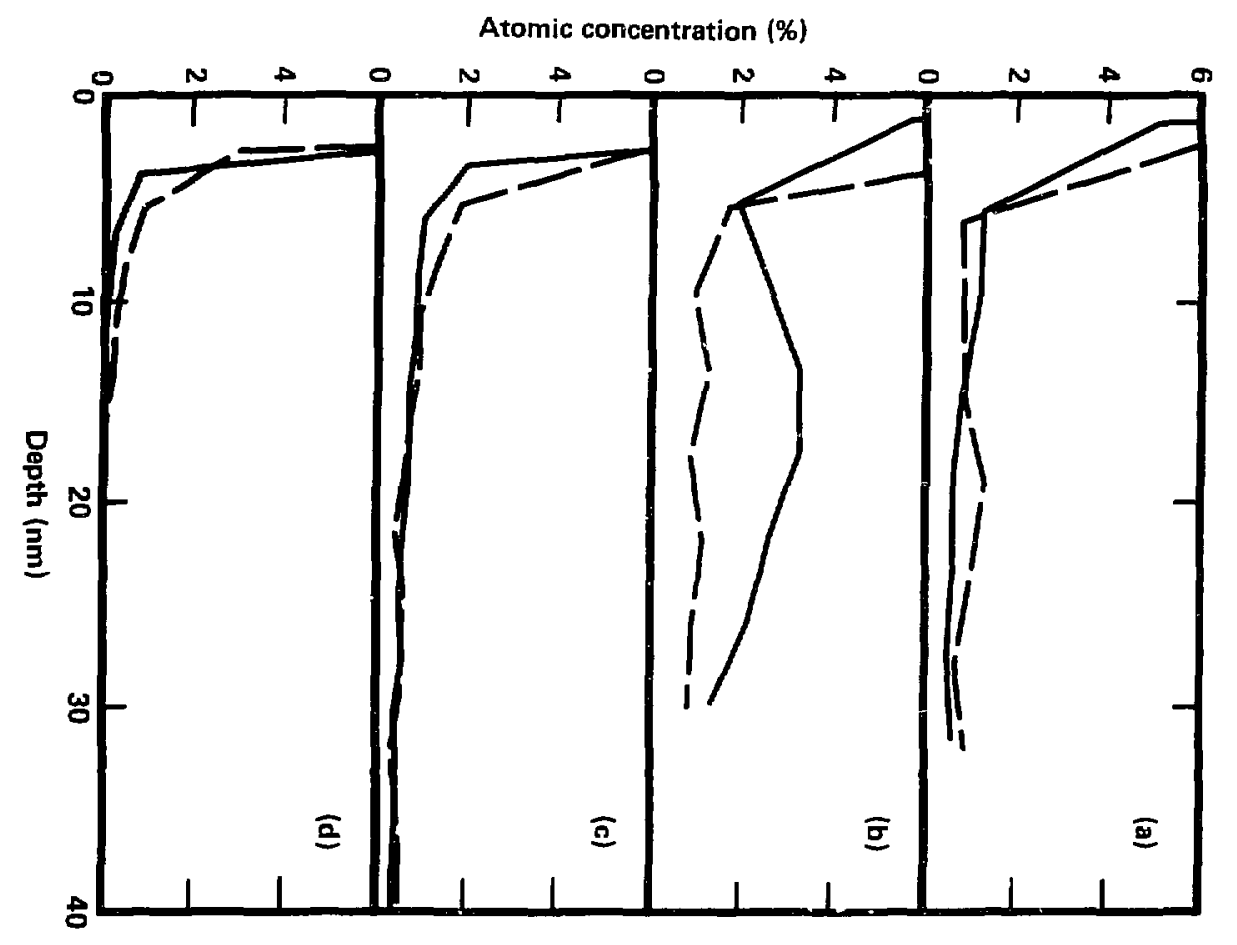

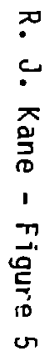

